\title{
Revision of Commonly Used Loop Knots Efficiencies
}

\author{
J. ŠIMON ${ }^{a, *}$, V. DEKÝS̆ ${ }^{b}$ AND P. PALČEK ${ }^{c}$ \\ ${ }^{a}$ Department of Applied Mathematics, Faculty of Mechanical Engineering, University of Žilina, \\ Univerzitná 8215/1,010 26 Žilina, Slovakia \\ ${ }^{b}$ Department of Applied Mechanics, Faculty of Mechanical Engineering, University of Žilina, \\ Univerzitná 8215/1,010 26 Žilina, Slovakia \\ ${ }^{c}$ Department of Materials Engineering, Faculty of Mechanical Engineering, University of Žilina, \\ Univerzitná 8215/1, 01026 Zilina, Slovakia
}

Received: 15.11.2019 \& Accepted: 24.04.2020

Doi: $10.12693 /$ APhysPolA.138.404

*e-mail: jan.simon@fstroj.uniza.sk

\begin{abstract}
In a number of professions, human life hangs on a knotted rope. However, until now only a poor attention of scientists has been paid to the properties of knots. The main objective of the presented research is to provide an in-depth revision of commonly used loop knot efficiencies employing modern experimental technologies and correct statistical processing. In the first part of the paper, the common mistakes in the available information sources were pointed out and the correct way of assessing the loop knot efficiency was proposed. Subsequently, correct statistical calculus was derived to evaluate mean knot efficiency and confidence interval. Efficiencies of eight commonly used loop knots loaded in several geometries were precisely measured, evaluated, and analyzed. Special attention was paid to avoid misleading conclusions based on experiments of low statistical power. Loop knot efficiency is not a constant, but it depends at least on the static breaking strength of a rope. The process of knot breakage was recorded by high-speed infrared thermal imaging. Analyses showed that the temperature of the most exposed parts of a knot could reach polyamide melting point. Finally, the microfilament analysis using electron microscopy was carried out to understand the breakage process on the microscopic level.
\end{abstract}

topics: knot efficiency, rope, tensile tests, thermal imaging, electron microscopy

\section{Introduction}

"Simply placing a knot in the rope before loading it will reduce its strength and, apart from the case of localized damage, the rope will always break at the knot. This weakness varies from 30 to $50 \%$, according to the kind of knot used." The author of this quotation is G. Marbach [1], a French pioneer of speleo-alpinism, and it briefly explains the reasons that led to the work on the submitted study between 2014 and 2019. A rope without a termination, respectively without an opportunity to form a solid connection between a rope and a manipulated object or a person, is in the most cases of no use. Technically undemanding, reversible, easy, fast, and probably the most frequently used way how to make a rope termination is to tie a loop knot. Unfortunately, only a few climbers, speleologists, workers at heights and mountain rescuers realize how a presence of a knot fundamentally affects rope breaking strength.

Available information sources represented especially by mountaineering textbooks, working guidelines, selected technical standards, specialized webpages, electronic articles and, to a certain extent, even scientific papers, show that the issue of a rope strength reduction due to presence of knot has been dealt with for a long time (for early experimental results see the following works $[2,3])$. Later on, works that dealt with the impact of various rope types and used materials on knot efficiency were written [4-10]. Among the first theoretical models that described friction and force distribution of certain knot types were works [11, 12]. These works were further supported by more precise models that focused also on the concentration of stress in the cross-sectional rope area, the mutual interaction of selected knotted structures [13-15], respectively rope contact with different surface types [16].

Several significant changes have taken place in rope production since the old adventurous and pioneering times. Producers have moved from the application of natural construction materials to synthetic materials with various surface modifications. The reason for this was mostly biological degradation of natural organic materials and a lower strength/mass ratio $[1,17]$. However, water, UV radiation, and mechanical strain still affect the properties and durability of modern ropes [18-21]. The shift towards synthetic materials and impregnation can be regarded as a crucial technological progress in rope making. 
Even the construction of low stretch ropes has been dramatically transformed, as a typical twisted rope has been substituted by so-called "kernmantle rope". Configuration with central loadbearing part "core", consisting of several twisted strands of evenly distributed chirality $S$ and $Z$ surrounded by "sheath" with both protective and bearing functions, improves knotability, and at the same time improves durability and safety of the rope $[1,22,23]$.

It is evident that modern ropes substantially differ from the ropes that were used by the older generation of climbers, speleologists, and rescue workers. Due to this change, the knot efficiencies required a general revision.

Within the previous 20 years, several works have been published with the ambition to fill the gap [24-34]. Many methodological guidelines and mountaineering textbooks have adopted the results of these works, unfortunately, including many of the errors. In the following text, we will try to point out frequent mistakes that can be found across the information sources. Namely,

- A small number of repeated experiments is usually one of the biggest problems. Results of our research clearly show that if we test the strength of the same rope repeatedly (with or without a knot), breaking strength may vary up to $40 \%$ of the average value.

- In most cases, incorrect mathematical methods are used to calculate knot efficiency. Depending on the type of rope, it can yield results with margin error up to $10 \%$.

- Imprecise or missing documentation of experimental setup, conditions and performance of experiments is a common mistake. Interpretation of such results is disputable, and a systematic error of unknown magnitude may skew the results.

- The photographic and image documentation in the published works reveals that knots were not always dressed correctly. Although it is well known that stress distribution within undressed knot is not optimal, a simple or even multiple crossing is a common mistake.

- Authors do not distinguish between a loop knot tied in geometry I and O (see Sect. 3.3). This happens even though there exist works assuming geometry $\mathrm{I}$ and geometry $\mathrm{O}$ are not equally efficient. Moreover, we may find cases in which the authors did not distinguish between standard load and cross-load of a loop knot.

- Unclear precision of experimental setup and absence of certifications on regular calibrations may affect results by an error of unknown significance.

- Some works do not distinguish between a failure of a knot by rope breakage and by untying, while both failures are of a different nature and absolutely incomparable.

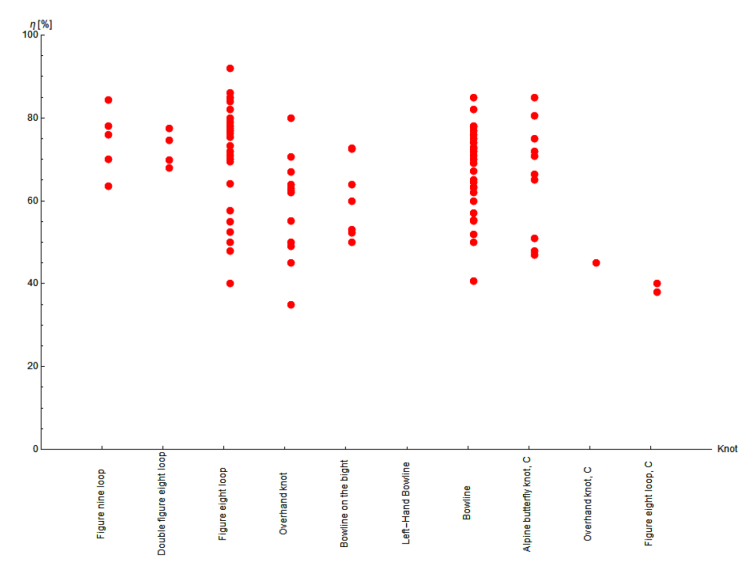

Fig. 1. A graphical comparison of loop knot efficiencies (data acquired from available information sources).

- Most authors have focused on a narrow range of knots. Only a few authors applied a uniform methodology in the whole range of knots that are used in mountaineering, speleoalpinism, and mountain rescue. Results that were consequently summarized in most of the textbooks are of poor importance as these results come from various sources. However, the results cannot be combined due to different methodologies of measurement, heterogeneous rope materials, and statistical processing applied.

- Available results are extremely heterogeneous. Their dispersion is so wide-ranged that even the accumulation of all the above-stated errors cannot explain it (see Fig. 1). One of the most important conclusions of the presented research is that the knot efficiency is most likely not a constant, but it at least depends on the static strength of a rope. It is clear that combining incompatible results of different experiments measured on different ropes must lead to an output of low informative value.

The submitted study has the ambition to avoid the above-mentioned mistakes and to provide the most objective information on a wide range of loop knots in all possible variants of load, tied on the latest generation of static ropes. Tests were performed using a uniform methodology, harmonized with existing standards when possible. Only certified and calibrated experimental setup was applied, an emphasis was laid on correct tying and dressing of knots and thorough photographic documentation. A number of experiments were selected in such a way to use experimental material most effectively and to get results of the highest possible statistical power. Measurements on older static ropes were also carried out to assess the effect of rope ageing on knot efficiency. The points with the increased concentration of stress and excessive friction were 
Parameters of tested ropes declared by the manufacturer, their mission, and stage of wear.

TABLE I

\begin{tabular}{|c|c|c|c|c|c|c|}
\hline Manufacturer & GILMONTE & BEAL & EDELWEISS & LANEX & EDELRID & LANEX \\
\hline Rope trademark label & $\begin{array}{c}\text { Profistatic } \\
10.5 \mathrm{~A}\end{array}$ & $\begin{array}{c}\text { Contract } \\
10.5\end{array}$ & Bud 10.5 & $\begin{array}{c}\text { TENDON } \\
\text { Static } 11 \mathrm{~mm}\end{array}$ & $\begin{array}{c}\text { Superstatic } \\
10.5 \mathrm{~mm}\end{array}$ & $\begin{array}{c}\text { TENDON } \\
\text { Static } 9 \mathrm{~mm}\end{array}$ \\
\hline Abbreviation & $\mathrm{G}$ & $\mathrm{B}$ & EW & L1 & $\mathrm{ER}$ & L2 \\
\hline EN standard Type & \multicolumn{6}{|c|}{ EN 1891} \\
\hline Type & \multicolumn{5}{|c|}{ type A rope } & type B rope \\
\hline Material & \multicolumn{6}{|c|}{ Polyamide } \\
\hline Year of manufacture & 2015 & 2006 & 2014 & 2006 & 2008 & 2004 \\
\hline Diameter $[\mathrm{mm}]$ & 10.5 & 10.5 & 10.5 & 11.0 & 10.5 & 9.1 \\
\hline $\begin{array}{l}\text { Static breaking } \\
\text { strength (Tenacity) }[\mathrm{kN}]\end{array}$ & 32 & 25 & 24 & 34.6 & 30 & 21.3 \\
\hline $\begin{array}{l}\text { Static breaking strength with } \\
\text { knot termination }[\mathrm{kN} / 3 \mathrm{~min}]\end{array}$ & 15 & 16 & 17 & 15 & $\mathrm{~N} / \mathrm{A}$ & 15 \\
\hline Weight per meter $[\mathrm{g} / \mathrm{m}]$ & 65.8 & 66 & 67 & 79.6 & 71 & 52.6 \\
\hline Impact force $f=0.3[\mathrm{kN}]$ & 5.9 & 5 & 5.6 & 5.55 & $\mathrm{~N} / \mathrm{A}$ & 4.12 \\
\hline $\begin{array}{l}\text { Number of falls } \\
\text { due to EN } 1891(f=1)\end{array}$ & 11 & 12 & 12 & 38 & $\mathrm{~N} / \mathrm{A}$ & 11 \\
\hline Sheath slippage $[\mathrm{mm}]$ & 0 & 0 & 0.2 & -2 & 0 & 0 \\
\hline Elongation [\%] & 3.4 & 2.9 & 3.1 & 3.7 & 4 & 4.9 \\
\hline Sheath mass [\%] & 37 & 39 & 36.4 & 41.8 & 45 & 49.2 \\
\hline Core mass [\%] & 63 & 61 & 63.6 & 58.2 & 55 & 50.8 \\
\hline $\begin{array}{l}\text { Shrinkage according } \\
\text { to EN } 1891[\%]\end{array}$ & 3.8 & 3.3 & 5 & 3.5 & 2.4 & 3.6 \\
\hline Knotability & 0.7 & $\mathrm{~N} / \mathrm{A}$ & 1.05 & 1.18 & 0.8 & 1.07 \\
\hline Core structure & $7 \mathrm{~S}+7 \mathrm{Z}$ & $5 \mathrm{~S}+6 \mathrm{Z}$ & $7 \mathrm{~S}+7 \mathrm{Z}$ & $8 \mathrm{~S}+8 \mathrm{Z}$ & $7 \mathrm{~S}+6 \mathrm{Z}$ & $4 \mathrm{~S}+5 \mathrm{Z}$ \\
\hline Rope mission and history & New, un & used & $\begin{array}{l}\text { Work at height } \\
\text { painting of vertical } \\
\text { constructions }\end{array}$ & Speleo-rescue & Speleo-rescue & $\begin{array}{l}\text { Mountain } \\
\text { rescue }\end{array}$ \\
\hline Wear stage & New, un & used & $\begin{array}{l}\text { Both sheath } \\
\text { and core affected } \\
\text { by colour }\end{array}$ & $\begin{array}{l}\text { Shea } \\
\text { pene }\end{array}$ & $\begin{array}{l}\text { th worn, no def } \\
\text { trating to the } \mathrm{c}\end{array}$ & \\
\hline Rope length [m] & 1010 & 100 & 60 & 200 & 90 & 50 \\
\hline
\end{tabular}

identified using high-speed infrared thermal imaging at the critical moments of knot breakage. A material analysis using electron microscopy was carried out to understand the principle of knot breakage on the structural level.

Terminology denoting knots, their parts, and division into groups is derived from works [35-38]. Stand - standing part is the rope or ropes that emerge from a knot and are loadbearing [36]. It is the long, unknotted segment of the rope, also referred to as the dead end, standing end and the dormant or stagnant part of the rope or line [38]. Wend - working end is the short rope segment, that emerges from a knot and is not intended to be loadbearing [36]. It is also the terminus of the cord employed to tie a knot [38].

Bight is a doubled-up section of rope. Knots tied on the bight are tied using a doubled-up section of the rope, often to produce two loops from a knot that normally only produces a single loop. Tying on the bight can also put a knot in the middle of a rope without the need to access to the ends of a rope [36]. Confusingly, bight also refers to a simple wrap or loop in a rope or cord, which can be an unfinished knot or a portion of a completed knot [38].
Dressing is the term used for the final arrangement of a knot into the correct pattern before it is loaded. Dressing is vital to make sure that the knot behaves, and has the breaking strength, as expected. Dressing a knot involves not only aligning loops and twists but also tightening the loops in the knot [36].

\section{Material and methods}

\subsection{Ropes}

Knots were tied on modern polyamide low stretch kernmantle ropes (EN 1891 standard type A and B). To ensure objectivity, both old and new ropes of various producers were tested. However, the ropes were made of the same material and manufactured by similar technology. Although, the age itself should not significantly affect the rope reliability if it is stored correctly [19], majority of mountaineering authorities, together with most of the producers, regard the rope age as a key feature determining its performance [39-46]. Rope's lifespan is also affected by the intensity of rope usage, especially top-rope climbing and rappelling [47]. Other factors 
TABLE II

Parameters of tested accessory cord declared by the manufacturer, its mission, and stage of wear.

\begin{tabular}{l|c}
\hline \multicolumn{1}{c}{ Manufacturer } & GILMONTE \\
\hline Accessory cord trademark label & Rep $8 \mathrm{~mm}$ \\
Abbreviation & G8 \\
EN standard & EN 564 \\
Material & Polyamide \\
Year of manufacture & $2015-2018$ \\
Diameter [mm] & 8 \\
Static breaking strength (Tenacity) [kN] & 18 \\
Weight per meter [g/m] & 40.2 \\
Core structure & $3 \mathrm{~S}+3 \mathrm{Z}$ \\
Mission and history & New, unused \\
Wear stage & New, unused \\
Rope length used for experimental & 562 \\
examination [m] &
\end{tabular}

are UV radiation, abrasive particles, acids and aggressive chemicals, temperatures above $50^{\circ} \mathrm{C}$, and weather conditions $[21,48,49]$.

The age of ropes used in the presented paper ranged from 1 to 12 years. The tested ropes were previously used for speleo-rescue, mountain rescue, and work at height.

Detailed characteristics of the tested ropes according to the EN 1891 standard and accessory cords according to the EN 564 standard are shown in Tables I and II.

\subsection{Tensile tests}

Breaking strength of ropes and knot efficiencies were tested using a horizontal testing device designed for static tests of climbing ropes. It was produced in 2006 by Engineering Test Institute, Public Enterprise (SZU), Brno. The device is mounted in ropemaking company Gilmonte, in a room with permanent laboratory conditions. Force measurements were performed by tensometric sensors connected to the control unit and a computer. Two opposite cylindrical self-locking jaws with the diameter of $120 \mathrm{~mm}$ were used to fix the rope. The rope was wrapped three times and pulled through the central gap, based on the principle of tensionless hitch. Hence, the rope was anchored purely by friction, gradually stretched in accordance with the EulerEytelwein equation [16] and was not exposed to strain in shear or twist. If required, one cylindrical jaw was used against which a smoothly polished steel ring simulating a climbing carabiner was placed. Jaw movement was provided by a hydraulic mechanism within a range of $0-3 \mathrm{~m}$. The speed of the jaw movement was set to $180 \mathrm{~mm} / \mathrm{min}$ according to the EN 364 standard. Calibration of the machine was performed once in two years by the independent institution Slovak legal metrology. A relative measurement error is guaranteed to be lower than $0.17 \%$ within the interval of acting forces.
2.3. High-speed infrared thermal imaging and rope emissivity

Recordings of temperature distribution within the knot body and surroundings were performed by the high frame rate infrared camera FLIR SC7500 with $\mathrm{InSb}$ detector $320 \times 256$ pixels at the native frame rate of $383 \mathrm{~Hz}$. Knot breakage is a relatively fast process that takes place in the course of $10^{-5}-10^{-4} \mathrm{~s}$. In order to record crucial stages of knot breakage, the frame rate was set up to $1253 \mathrm{~Hz}$. Thus, individual images were taken in $0.8 \mathrm{~ms}$ intervals. The camera worked in the superframing mode with three integrated times (from 19 up to $433 \mu \mathrm{s}$ ), with the objective L0116 or L0106 with the focal length 25 or $50 \mathrm{~mm}$, IFOV $=0.6 \mathrm{mrad}$. The whole infrared system was mounted on a tripod at a distance of $1.5-1.7 \mathrm{~m}$ from the breakage zone. The field of view was thermally separated from the surrounding environment by polystyrene panels.

A crucial factor in the process of recorded signal transformation to thermal imaging is the emissivity. Measurement of this quantity is nontrivial and requires specialized experimental devices. Therefore, we established a collaboration with the New Technologies-Research Centre at the University of West Bohemia. Here the emissivity was directly measured for the whole Gilmonte Profistatic rope, as well as for the isolated core at polar angle $10^{\circ}$ and various temperatures. The method of measurement of the effective directional emissivity at high temperature (EDEHT) is described in the following works $[50,51]$. Results of emissivity measurements are available in Tables III and IV.

\subsection{Electron microscopy}

The nature of individual microfilaments damage before and after knot breakage was investigated by the scanning electron microscope TESCAN VEGA II LMU. Since microfilaments are electrical insulators, detector LVSTD was used to scan the surface of broken fibers without metallization.

TABLE III

Emissivity $\varepsilon$ of core measured on rope GILMONTE Profistatic 10.5.

\begin{tabular}{c|c|c|c|c|c|c}
\hline \hline$T\left[{ }^{\circ} \mathrm{C}\right]$ & 50 & 100 & 150 & 180 & 190 & 200 \\
\hline$\varepsilon$ & 0.795 & 0.804 & 0.779 & 0.853 & 0.869 & 0.865 \\
Std. dev. & 0.103 & 0.062 & 0.046 & 0.044 & 0.043 & 0.041
\end{tabular}

TABLE IV

Emissivity $\varepsilon$ of whole rope (core + sheath) measured on rope GILMONTE Profistatic 10.5.

\begin{tabular}{c|c|c|c|c}
\hline \hline$T\left[{ }^{\circ} \mathrm{C}\right]$ & 50 & 100 & 150 & 180 \\
\hline$\varepsilon$ & 0.801 & 0.834 & 0.833 & 0.844 \\
Std. dev. & 0.104 & 0.066 & 0.050 & 0.087
\end{tabular}




\section{Results and discussion}

\subsection{Rope without a knot}

The measurement of the straight rope static breaking strength is the first step in the calculation of knot efficiency. Symbol $y$ has been reserved to label this quantity in the following text.

Statistical analysis confirmed that the static breaking strength of a rope can be regarded as normally distributed with mean value $\bar{y}$ and variance $\sigma_{0}^{2}=\overline{(y-\bar{y})^{2}}$. Therefore, we can write the probability density function of static breaking strength by the following formula:

$$
\rho_{0}(y)=\frac{1}{\sqrt{2 \pi} \sigma_{0}} \exp \left(-\frac{(y-\bar{y})^{2}}{2 \sigma_{0}^{2}}\right) .
$$

Experimental results proved that $\bar{y} /\left(\sqrt{2} \sigma_{0}\right) \gg 1$ and so we can state that $\int_{0}^{\infty} \rho_{0} \mathrm{~d} y \cong \int_{-\infty}^{\infty} \rho_{0} \mathrm{~d} y=1$. Therefore,

- Despite the fact that the negative strength does not have any physical sense, it can be considered as the normally distributed quantity.

- Regardless of the age but depending on the degree of wear, a rope is a heterogeneous structure with variable strength from one place to another. Differences in static breaking strength of adjacent parts of the same rope can reach up to $40 \%$ of an average value. Due to this fact, any conclusions on rope strength, with or without knots, can be based only on a set of representative measurements yielding results of high statistical significance.

- According to rope producers, if properly stored, rope ageing is not harmful to ropes for a certain period [42-46]. Results of our tests confirm these statements; properly stored old rope performed as a new one even after 10 years.

- The static breaking strength of a rope decreases by rope usage. Within the performed experiments we recorded a decrease by $7-24 \%$ in static breaking strength when compared to a new rope.

- Statistical analysis neither confirmed nor disputed the weakening of the central and terminal parts of a rope.

3.2. Rope terminated by a loop knot: statistical properties of the knot efficiency

A rope in which a knot is tied always shows lower static breaking strength compared to the rope without a knot. The effect has been known for a long time and the term knot efficiency or residual breaking strength (RBS) was adopted for its quantification. Knot efficiency is defined as a proportion of static breaking strength of a rope in which the knot is tied (marked as $x$ ) and static breaking strength of the same rope without the knot (marked as $y$ ). Knot efficiency $\eta=\frac{x}{y}$ is usually expressed in a percentage.

Breaking strength of rope with or without a knot can be measured directly, but knot efficiency cannot. That is why we must evaluate knot efficiency by a calculation.

Statistic tests confirmed that static breaking strength of the rope with a knot termination is normally distributed around the mean value $\bar{x}$ with a variance $\sigma^{2}=\overline{(x-\bar{x})^{2}}$. Therefore, we can write the probability density function of the static breaking strength of rope terminated by a knot by the following formula:

$$
\rho(x)=\frac{1}{\sqrt{2 \pi} \sigma} \exp \left(-\frac{(x-\bar{x})^{2}}{2 \sigma^{2}}\right) .
$$

Experimental results proved that $\bar{x} /(\sqrt{2} \sigma) \gg 1$ and so we can state that $\int_{0}^{\infty} \rho \mathrm{d} x \cong \int_{-\infty}^{\infty} \rho \mathrm{d} x=1$. Therefore, despite the fact that the negative strength does not have any physical sense, it can be considered as the normally distributed quantity.

It can be shown that the knot efficiency falls within the interval $\langle\eta, \eta+\mathrm{d} \eta\rangle$ with probability $P_{\langle\eta, \eta+\mathrm{d} \eta\rangle}=\int_{0}^{\infty} \int_{\eta y}^{(\eta+\mathrm{d} \eta) y} \rho \rho_{0} \mathrm{~d} x \mathrm{~d} y$, where $\rho$ and $\rho_{0}$ are defined by (1) and (2). After evaluation of inner integral we get the probability density function of knot efficiency

$$
\rho_{\eta}(\eta)=\int_{0}^{\infty} y \rho(\eta y) \rho_{0}(y) \mathrm{d} y .
$$

Distribution $\eta_{\rho}$ is not symmetric (see Fig. 2) and it is clear that the mean knot efficiency cannot be calculated by the relation $\bar{\eta}=\frac{\bar{x}}{\bar{y}}$ as is widely used by authors, but by integral $\bar{\eta}=\int_{0}^{\infty} \eta \rho_{\eta}(\eta) \mathrm{d} \eta$. Using Monte Carlo method, we estimated that incorrect technique of the calculation can lead to an error up to $5-10 \%$ when compared to formula (3).

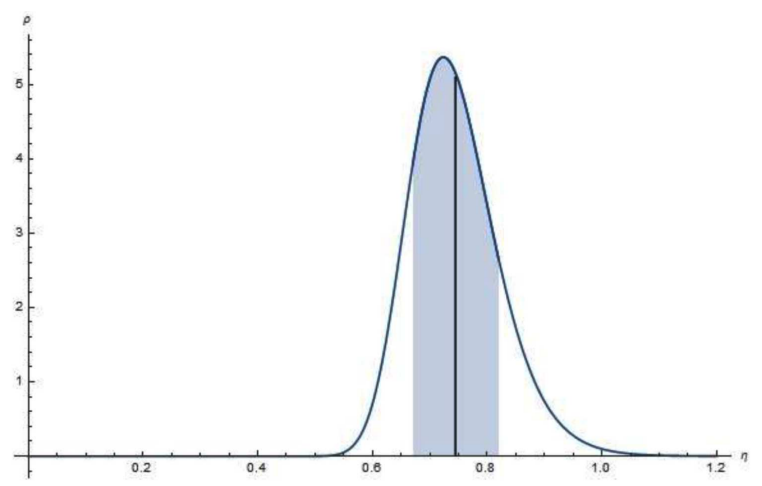

Fig. 2. An example of the probability density function of the standardly loaded figure eight loop (geometry I) given by (3). Black line represents mean value; $68.27 \%$ of all measurements fall within the blue shaded interval. 
Exactly $68.27 \%$ of all results fall within the confidence interval $\left\langle\eta_{L}, \eta_{H}\right\rangle$, where $\int_{0}^{\eta_{L}} \rho_{\eta}(\xi) \mathrm{d} \xi=15.87 \%$ and $\int_{\eta_{H}}^{\infty} \rho_{\eta}(\xi) \mathrm{d} \xi=15.87 \%$ Interval $\left\langle\eta_{L}, \eta_{H}\right\rangle$ is a non-symmetric analogy to the $1-\sigma$ confidence interval of normal distribution.

\subsection{Loop knots in general}

Loop knot is a knotted structure that features one or more loops. Loops can be fixed, slippery or adjustable. Some slip loops can collapse down to a simpler knot or, if not attached to another object, become untied entirely when loaded. In general, a loop maintains its structure even when removed from its point of attachment [38]. Loop knots can be loaded under standard load, cross load and ring load [52-54].

When a loop knot is under standard load, a pair of opposing and equal forces act on the stand and the loop. Vectors of both forces lie on a straight line which is usually equal to the longitudinal knot symmetry axis. Standard load is an optimal way to load a loop knot as it resists both untying and breakage better than under any other conditions. There are two possible ways how to tie the vast majority of loop knots, thus let us call them geometry I and geometry $\mathrm{O}$ (Fig. 3). They can be characterized as follows:

- In geometry I, the stand and the wend twist around the loop in such a way that the stand is on the inside and the wend on the outside of the undressed collar. Stand is proximal and wend distal to the loop on the dressed loop knot;

- In geometry $\mathrm{O}$, the stand and the wend twist around the loop in such a way that the stand is on the outside and the wend on the inside of the undressed collar. Stand is distal and wend proximal to the loop on the dressed loop knot;

- When loop knot is under cross-load, a pair of opposing and equally powerful forces acts on the wend and the stand. There are additional strain components in the rope that are not present in the standardly loaded knot. That is why the efficiency of cross-loaded loop knots is significantly lower. Loop is usually loaded by negligible small force when compared to forces acting on stand and wend. If knot has the longitudinal axis of symmetry, then acting forces lie on the straight line which is approximately perpendicular to it (Fig. 3);

- When loop knot is under ring-load, two or more forces act on the loop so that their vector sum is zero. Approximately half of the acting force is transmitted to the knot. Part of the ring-load can be dissipated by friction between the loop and anchoring object.

It is also possible to load a loop knot by the combination of the above-mentioned loads. However, we did not consider these in our research.

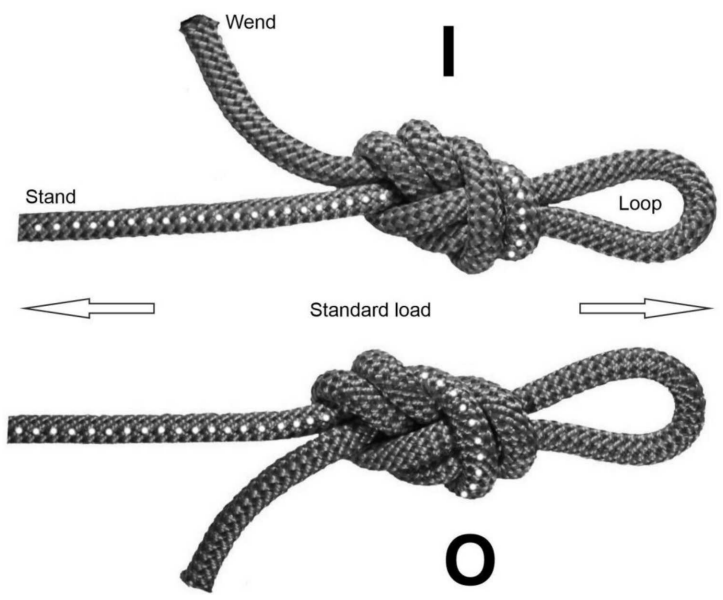

Fig. 3. Standardly loaded figure eight loop (geometry I and $\mathrm{O}$ ).

In the presented study, we have experimentally investigated the following loop knots: figure eight loop, double figure eight loop, figure nine loop, overhand knot, bowline, left-hand bowline, bowline on a bight and alpine butterfly knot, which are among the most commonly used knots in their category.

\subsubsection{Figure eight loop}

Figure eight loop (Flemish loop, ABOK \#1047) is one of the most widely used single-loop knots. Therefore, we set it as a referential benchmark in the following text.

The vast majority of methodological materials recommend it as a first choice how to attach a rope to a harness (so-called tie-in) because of its relative simplicity, reliability, symmetry, and easy visual partner check. Real-life situations have proved that properly tied figure eight loop is more reliable than more complicated knots tied in the wrong way. It is used for multiple purposes, but mainly to tiein, to form a rope termination for single loop anchoring in mountaineering, mountain rescue, speleoalpinism and work at height. It is recommended to tie this knot using ropes with a diameter of at least $9 \mathrm{~mm}$ as it can be hard to untie after heavy loading or fall arrest [1, 40, 41, 55-60].

It can be tied on a bight (using a carabiner or a post), as well as at the end of a rope around the closed anchoring point (so-called rewoven or rethreaded figure eight, tied by rethreading figure eight stopper ABOK \#524 in reverse).

It is possible to load it standardly in both geometries I and O (Fig. 3), under cross-load (Fig. 4) or ring-load. Standardly loaded figure eight loop in geometry I is also recognized by EN 1891 and EN 892 as a rope termination for tensile tests. It does not tend to untie under cyclic loading. Figure eight loop was tested under standard loading (in both geometries I and O) and cross-load in the presented study (see Fig. 5). One can observed that 


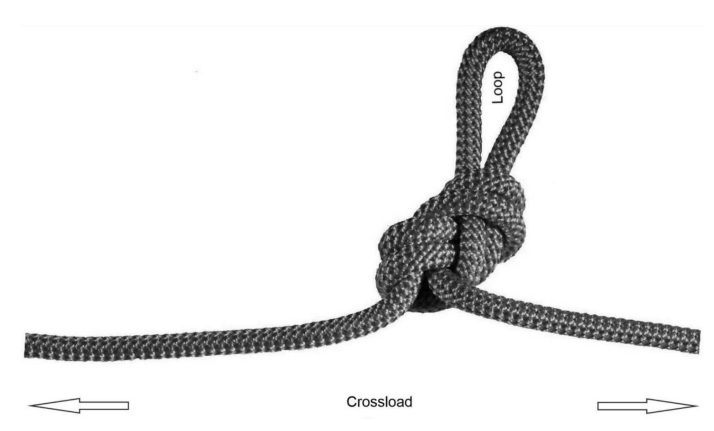

Fig. 4. Cross-loaded figure eight loop.

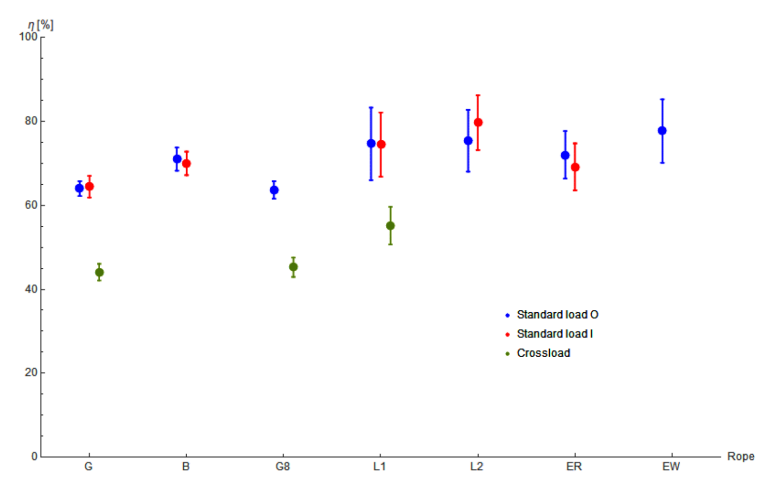

Fig. 5. Figure eight loop efficiency.

- The efficiency of standardly loaded figure eight loop in $\mathrm{O}$ and I geometry is statistically indistinguishable at the significance level $5 \%$. Therefore, we can consider the efficiency in both geometries to be the same. This conclusion is supported by a total of 81 measurements using five different ropes, and it is in direct contradiction to the following works $[7,8,36,56,61,62]$.

- Figure eight loop is one of the most widely used knots. Therefore, we paid special attention to its experimental examination. We measured its efficiency in standard loading on 11 different ropes of comparable diameter. We found out that the results differ up to $16 \%$, although experimental conditions were identical and the experimental setup error was negligible. In order to explain this phenomenon, we correlated the efficiency with the different parameters of the rope on which the knot was tied. An interesting result was found when we related the efficiency to the static breaking strength of the rope (Fig. 6). In all likelihood, the efficiency of the standardly loaded figure eight loop is a decreasing function of the static breaking strength of the rope. Under first-order approximation this function can be linearized by

$$
\eta(y) \cong-0.77(y-32.79)+66.45 \%
$$

(correlation coefficient $R^{2}=0.67$ ).

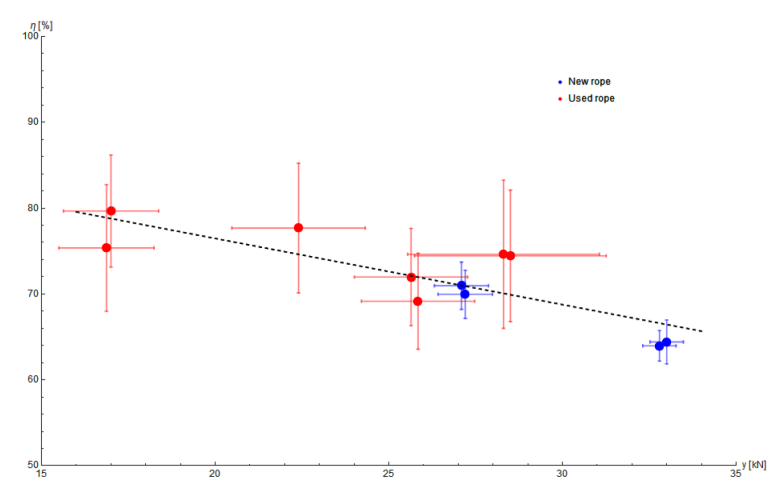

Fig. 6. Standardly loaded figure eight loop efficiency as a function of the static breaking strength of the rope.

Thus, the efficiency of the standardly loaded figure eight loop is very unlikely to be a constant, contrary to what all available publications implicitly present. This statement may also be generalized to other loop knots, but it would require further experimental evidence. If the formulated hypothesis is correct, then it makes no sense to compare the efficiency of the knots tied on different ropes.

This result can be indirectly supported by several works $[63,64]$, which attempted to correlate various knot efficiencies with a rope diameter. Evans [65] in his article concluded that there is a trend for knots in larger diameter materials to retain less of the original unknotted strength. To make the linkage clear, let us briefly acknowledge that the static breaking strength of rope $y$ and rope diameter $r$ are under second-order approximation coupled by increasing relation $y \approx r^{2}$.

The efficiency of a cross-loaded figure eight loop was determined on two ropes and one accessory cord. In comparison to the standard loading, the measured efficiency was lower by $19.26 \pm 0.44 \%$. As a rule of thumb, it should be kept in mind that the cross-load reduces the efficiency of the figure eight loop by $\approx 20 \%$.

\subsubsection{Double figure eight loop}

Double figure eight loop (bunny ears, ABOK \#1085) is a knot of the figure eight loop group. However, it has two loops available for anchoring (see Fig. 7). As a result, it better resists ring-load, or loop cut at high forces and small curvature radii of the anchoring point. Another advantage is that it is easier to untie after heavy load and to adjust the size of the individual loops, used for example in building a multi-point equalized anchor [55, 56, 60]. It is tied mainly on a bight using a carabiner or a post. It is theoretically possible, but much more complicated, to tie the knot around a closed anchor point. It is possible to load it standardly in both $\mathrm{I}$ and $\mathrm{O}$ geometries, as well as under crossload and ring-load. 


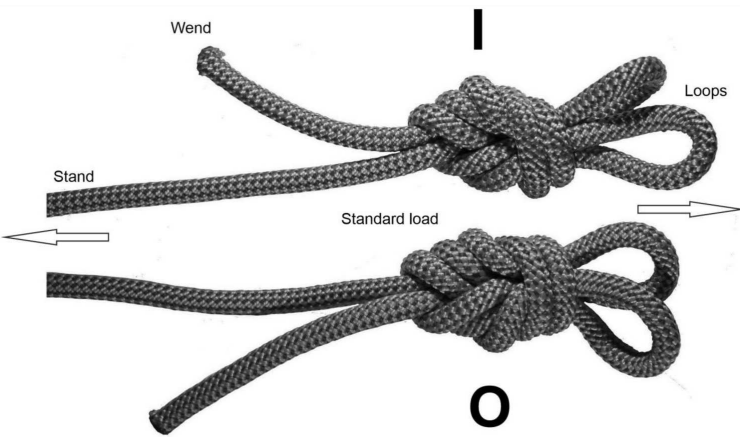

Fig. 7. Standardly loaded double figure eight loop (geometry I and $\mathrm{O}$ ).

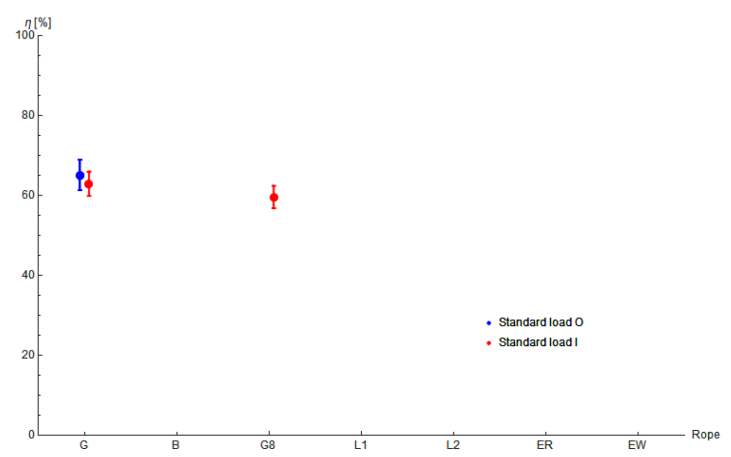

Fig. 8. Double figure eight loop efficiency.

Double figure eight loop was tested in standard loading in both geometries I and $\mathrm{O}$ (see Fig. 8). One can observed that

- The efficiency of the standardly loaded double figure eight loop in geometry $\mathrm{O}$ and I is statistically indistinguishable at a significance level $5 \%$. Therefore, we can consider the efficiency in both geometries to be the same. This conclusion is supported by a total of 22 measurements that were performed on the same rope.

- The difference in the efficiency of the standardly loaded double figure eight loop compared to the referential figure eight loop is statistically indistinguishable at a significance level $5 \%$. This conclusion is supported by a total of 44 measurements performed on the same rope in both geometries $\mathrm{O}$ and $\mathrm{I}$. Based on these results, we can conclude that double figure eight loop does not perform better than a much simpler figure eight loop.

\subsubsection{Figure nine loop}

Figure nine loop (rethreaded version of ABOK \#521) is one of the newest single-loop knots belonging to the figure eight knot group. However, it has a more complex structure compared to the figure eight knot (see Fig. 9), thus the strain is better distributed within the whole knot. After a heavy load or fall arrest, the figure nine loop does not require such a great effort to untie as compared to figure

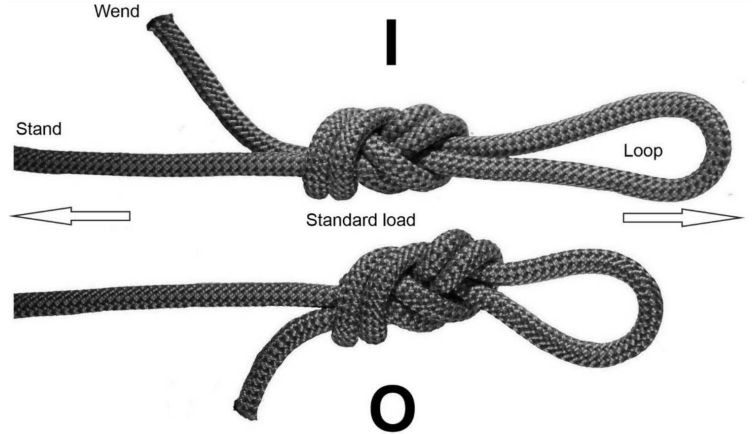

Fig. 9. Standardly loaded figure nine loop (geometry I and $\mathrm{O}$ ).

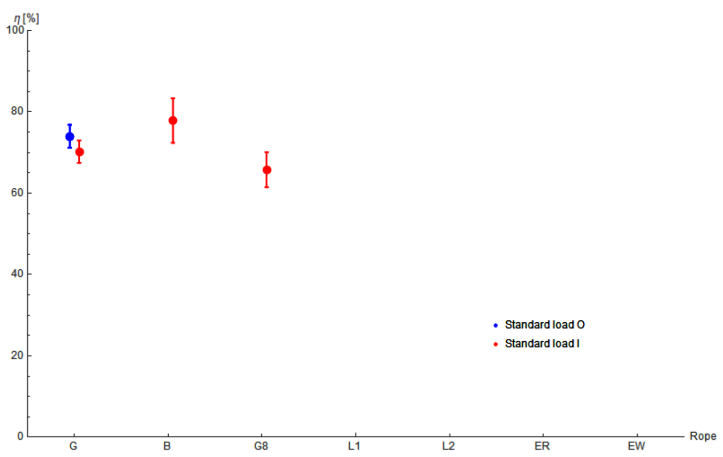

Fig. 10. Figure nine loop efficiency.

eight loop [57]. Given the higher efficiency, it works better with ropes of smaller diameter than the figure eight loop [55, 66]. However, figure nine knot is slightly more difficult to tie so there is a risk of making a mistake when tying or dressing it. Moreover, it is necessary to count with higher rope consumption [1]. Compared to figure eight loop, it fills by approximately 10\% larger volume. Thus, attention should be paid to prevent the knot from damage by excessive rubbing against a rock [56]. This type of rope termination can be tied on a bight (using a carabiner or a post) as well as by rethreading figure nine stopper (ABOK \#521) around a closed anchor point. The knot does not tend to untie under cyclic loading.

It is possible to load it standardly in both I and O geometries, under cross-load, as well as ring-load. Figure nine loop was tested under standard load in both I and $\mathrm{O}$ geometry (see Fig. 10). One can observed that

- The efficiency of a standardly loaded figure nine loop is not the same in geometries $\mathrm{O}$ and I (it is statistically distinguishable) at a significance level $5 \%$. The efficiency in geometry $\mathrm{O}$ is about $3.75 \%$ higher compared to geometry I. This conclusion is supported by a total of 19 measurements that were performed on the same rope. In the future, it is necessary to verify this conclusion by an independent experiment using multiple ropes. 


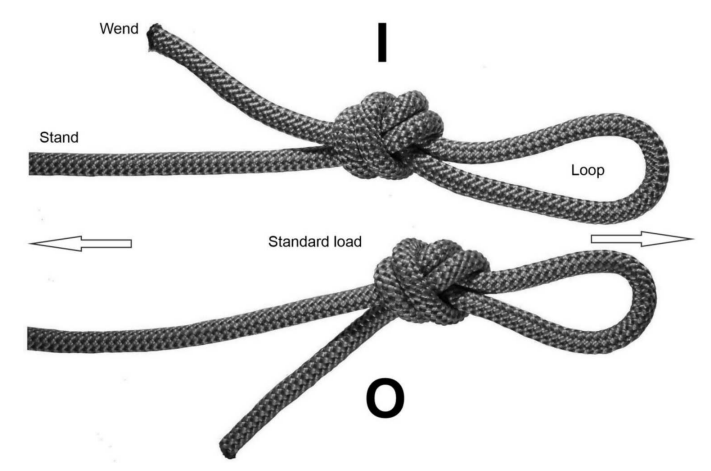

Fig. 11. Standardly loaded overhand loop (geometry I and $\mathrm{O})$.

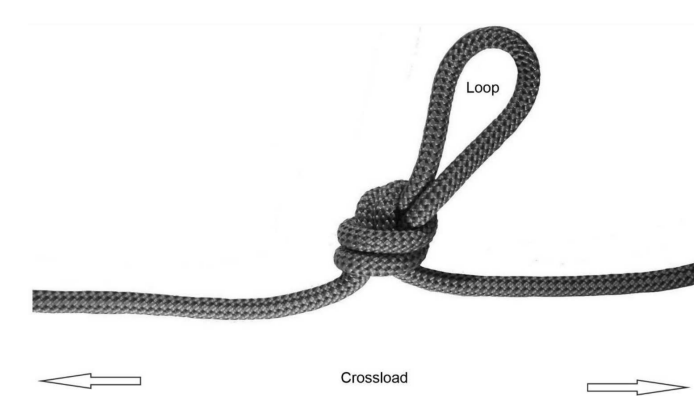

Fig. 12. Cross-loaded overhand loop.

- Standardly loaded figure nine loop proved to have the highest efficiency of all loop knots presented in this study in all of the tested geometries. When compared to a referential figure eight loop, the difference in the efficiency is $\Delta \eta_{\mathrm{O}}=+10.03 \%$ and $\Delta \eta_{\mathrm{I}}=+5.83 \%$. Based on the results, we recommend using the figure nine loop in $\mathrm{O}$ geometry for anchoring in the situations where high static loads are expected (e.g. high angle rescue techniques)

\subsubsection{Overhand loop}

Overhand loop (loop knot, overhand knot on a bight, ABOK \#1009) is one of the simplest singleloop knots with low rope consumption and a high degree of symmetry. Due to these benefits, it is popular and widely used. On the other hand, it is challenging to untie the knot after heavy load, especially when soft ropes with a diameter of $9 \mathrm{~mm}$ or less are used. It is usually tied on the bight in the middle of a rope to tie-in, as a fall arresting knot on glacier travel, as a leg loop on an accessory cord, or as a simple accessory knot in climbing where no dynamic stress is expected $[1,40,41,56,58]$. This rope termination can be tied on a bight (using a carabiner or a post) as well as rethreaded overhand knot stopper (ABOK \#46) around a closed anchor point. This knot is also preferred when rappelling to tie together two ropes of the same diameter $[40,41]$. In terms of the force, we can speak de facto about cross-loaded overhand loop knot (in this case the knot is called offset overhand bend, ABOK \#1410).

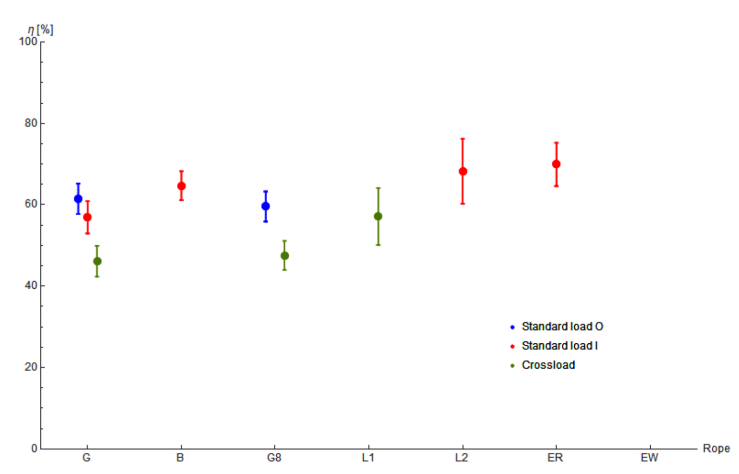

Fig. 13. Overhand loop efficiency.

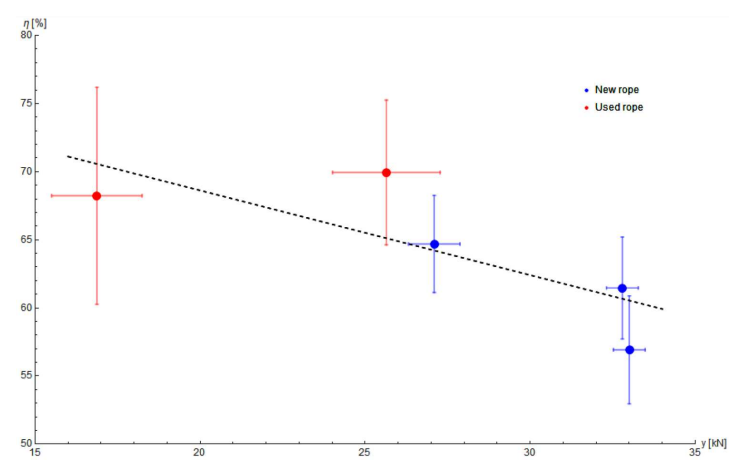

Fig. 14. Standardly loaded overhand loop efficiency as a function of the static breaking strength of the rope.

It is possible to load it standardly in both I and O geometries, under cross-load and ring-load (see Fig. 11 and 12). Overhand loop was tested under standard load (in both $\mathrm{I}$ and $\mathrm{O}$ geometries) and cross-load (see Fig. 13). One can observed that

- The efficiency of standardly loaded overhand loop in $\mathrm{O}$ and I geometries is not the same (it is statistically distinguishable) at a significance level 5\%. The efficiency in geometry $\mathrm{O}$ is slightly higher by $4.45 \%$ compared to geometry I. This conclusion is supported by a total of 24 measurements performed on the same rope. In the future, it is necessary to verify this conclusion by an independent experiment using various ropes. Since then we recommend to prefer overhand loop in geometry $\mathrm{O}$, at least in life-critical applications.

- Overhand loop is one of the most popular knots; therefore, we paid special attention to experimental examination of this knot. We measured its efficiency under standard load using 5 different ropes of a comparable diameter. The results show that the efficiency of the standardly loaded overhand loop to a first approximation is a linearly decreasing function of the static breaking strength of the rope (see Fig. 14):

$$
\eta(y) \cong-0.62(y-32.79)+60.67 \% .
$$


Thus, we have another good reason to believe that in general the efficiency of the standardly loaded loop knots is not constant.

Compared to a referential figure eight loop, the standardly loaded overhand loop proved to have lower efficiency in geometry I, $\Delta \eta_{\mathrm{I}}=-6.39 \pm 1.75 \%$ at a significance level of $5 \%$. In geometry $\mathrm{O}$, the efficiency of both knots is at the resolution threshold and its difference is $\Delta \eta_{\mathrm{O}}=-3.29 \pm 1.10 \%$. However, the lower efficiency was proven only on unused ropes. For used ropes, the variance of measured values is so extensive that the efficiency of knots cannot be statistically distinguished. These conclusions are supported by a total of 108 measurements that were performed on five different ropes in both $\mathrm{O}$ and I geometry. The efficiency of the cross-loaded figure eight loop and overhand loop is statistically indistinguishable at a significance level of $5 \%$. This conclusion is supported by a total of 48 measurements that were performed on three different ropes. Based on the findings, the overhand loop is more suitable in situations when static cross-load is expected (tying-in at glacier travel) thanks to easier tying and lower rope consumption.

\subsubsection{Bowline}

Bowline (single bowline, bowling, ABOK \#1010) is a single-loop knot and can be used for singlepoint anchoring (see Fig. 15). In the past, it has been used for tie-in to a harness. It is characterized by low rope consumption, simplicity, and speed of tying. Furthermore, it is possible to tie the knot with one hand.

Unlike the knots of the figure eight group, the bowline can be easily untied even after being exposed to an intense load. The wend does not rethread the basic stopper structure and I or O geometry is not defined. The main disadvantage of a bowline is that it is not inherently secure. It means that it can untie at relatively low forces when ringloaded, therefore stopper knot is mandatory [58]. Furthermore, it tends to spontaneously loosen under cyclic loading and can be tricky to inspect as it is not symmetric.

For the reasons mentioned above, it is not recommended to use this knot in life-critical applications anymore $[47,55,56,60,67]$. With a heavy rope strain, a bowline knot can capsize (twist to a position in which it is easy to untie). However, if the knot is tied correctly, there is little or no danger of capsizing before the breaking point of

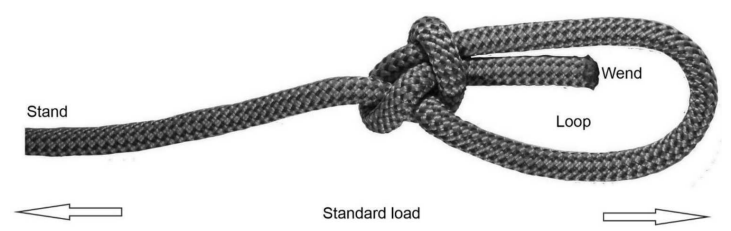

Fig. 15. Standardly loaded bowline.

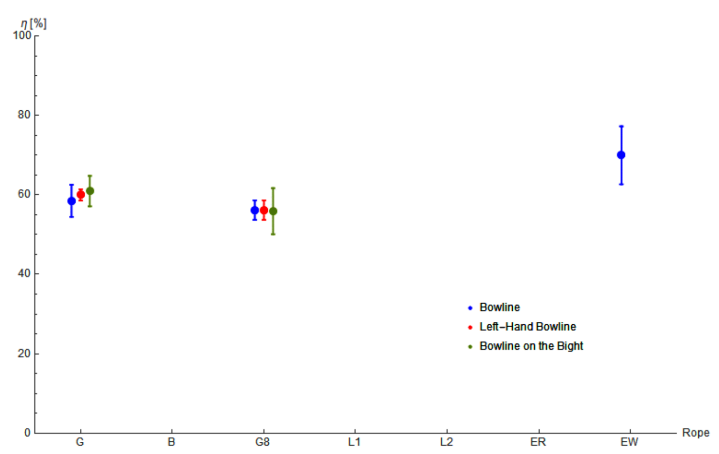

Fig. 16. Bowline, left-hand bowline, and bowline on a bight efficiency, standard load.

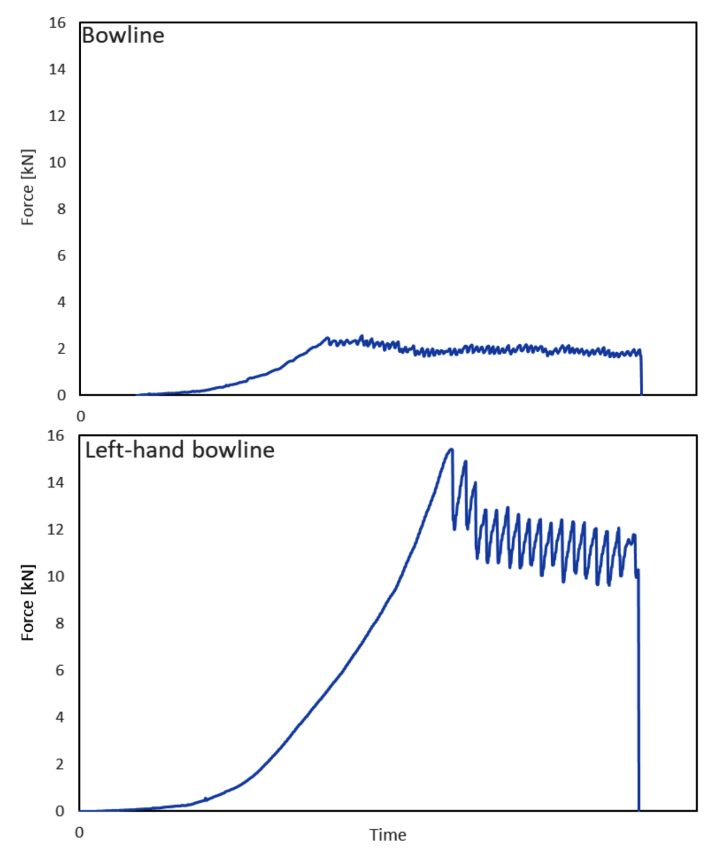

Fig. 17. Force applied over time by ring-load to bowline and left-hand bowline.

the rope itself is reached [35]. Bowline can be reasonably tied only at the end of a rope and therefore was tested under standard load and ring-load (see Figs. 16 and 17).

\subsubsection{Left-hand bowline}

Left-hand bowline (cowboy bowline, ABOK $\# 1034 \frac{1}{2}$ ) is a single-loop knot and it differs from the bowline by having wend on the outside of the loop (see Fig. 18). It has significantly better properties under ring-load than the bowline knot. The knot has a tendency to spontaneously loosen under cyclic loading [67]. Various attributes are assigned to this knot even in respected literature. However, validity of these attributes is at least disputable. Similarly to bowline, it is not inherently secure and therefore not recommended to use in lifecritical applications.

Left-hand bowline was tested under standard load and ring-load (see Figs. 16 and 17). 


\subsubsection{Bowline on a bight}

Bowline on a bight (ABOK \#1080) is a doubleloop knot of the bowline group (see Fig. 19). The advantage is its higher reliability and the possibility to adjust the size of individual loops for multipoint anchoring. Compared to the double figure eight loop, it is more compact, the rope consumption is lower, and it is easy to adjust the loop size [1]. It is tied mainly on a bight using a carabiner or a post. It is possible, but much more complicated, to tie it around a closed anchor point.

It is possible to load it standardly in both geometries I and $\mathrm{O}$, both under cross-load and ring-load. Bowline on a bight was tested under standard load in geometry I (see Fig. 16). One can observed that

- The efficiency of standardly loaded bowline, left-hand bowline and bowline on a bight in geometry I is statistically indistinguishable at a significance level 5\%. Therefore, the efficiency of all three knots can be considered the same. This conclusion is supported by a total of 51 measurements and it is in direct contradiction with proposition in the book [40], according to which left-hand bowline is "much weaker".

- All standardly loaded knots of the bowline group have lower efficiency when compared to referential figure eight loop at a significance level $5 \%$. The difference in the efficiency is $\Delta \eta=-4.64 \pm 1.53 \%$. These conclusions are supported by a total of 101 measurements that were done on three different ropes.

- Bowline and left-hand bowline were also tested under ring-load. None of the knots broke, but both of them untied. Therefore, it is irrelevant to talk about their efficiency when ring-loaded. The process of untying has two phases. In the first phase, the grip of the nipping turn is sufficient to resist the ringload. When the strain exceeds the threshold (let us call it $F_{0}$ ), the wend starts to move and the knot begins to slip periodically. This force has an average size $F_{0 \mathrm{~B}}=1.95 \pm 0.18 \mathrm{kN}$ for bowline and $F_{0 \mathrm{LHB}}=10.77 \pm 1.82 \mathrm{kN}$ for left-hand bowline. In a short period, due to the friction and heat, the rope sheath gets smoother and the friction force decreases to the level $F_{1}$. The average value of this force is $F_{1 \mathrm{~B}}=1.63 \pm 2.34 \mathrm{kN}$ for bowline and $F_{1 \mathrm{LHB}}=11.33 \pm 0.97 \mathrm{kN}$ for left-hand bowline. As the results show, the difference in the disintegration force between a bowline and left-hand bowline is statistically unquestionable. In conclusion, the left-hand bowline withstands the static ring-load better than the bowline (see Fig. 17). However, in both cases, the knots became unstable under cyclic loading and untied at relatively low forces when ring-loaded. Therefore, we do not recommend to use these knots in life-critical applications.

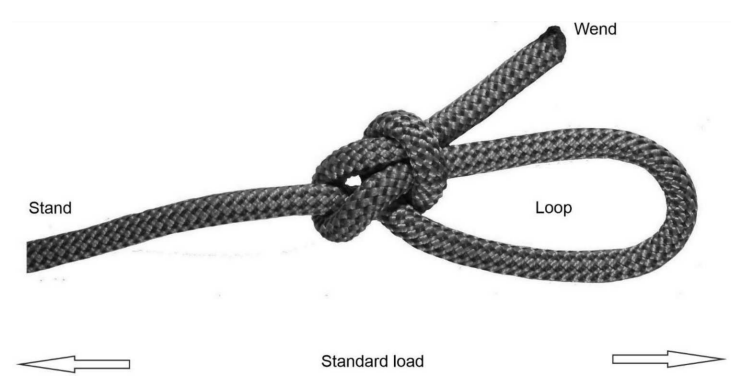

Fig. 18. Standardly loaded left-hand bowline.

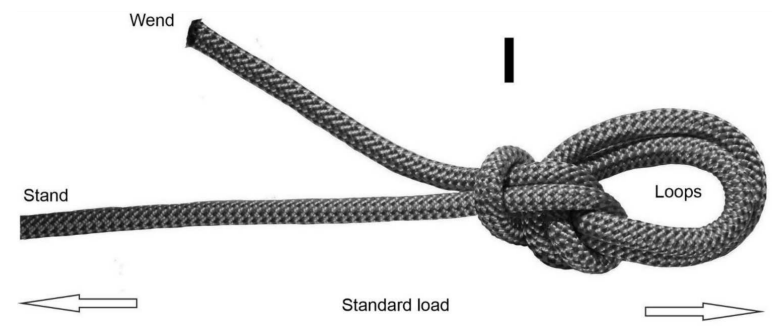

Fig. 19. Standardly loaded bowline on a bight (geometry I).

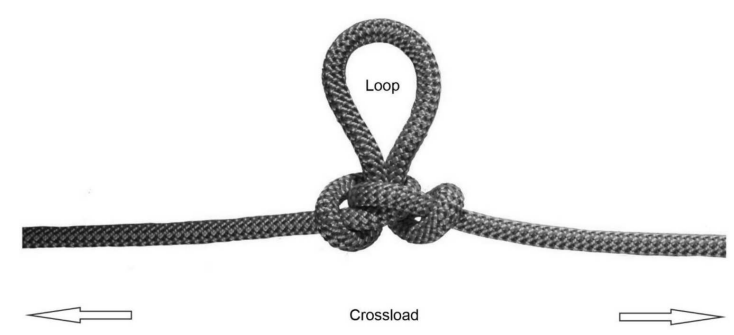

Fig. 20. Cross-loaded alpine butterfly knot.

\subsubsection{Alpine butterfly knot}

Alpine butterfly knot (Lineman's knot, ABOK $\# 1053$ ) is a single-loop knot. It is usually tied in the central part of the rope and it is unique as the wend opposes the stand (see Fig. 20). This makes it significantly different from most of the loop knots that are much more weakened by cross-load. When tying, it is necessary to pay attention in order to avoid tying its clone (so-called false butterfly knot), which slips at a lower force and is suitable as a shock-absorbing knot [1]. Due to its stability and optimal position of wend and stand under crossload, alpine butterfly may be used as a tie-in knot in a middle rope section for a glacier travel [59]. It is also used for anchoring hand lines and fixed ropes in traverses or disengaging shorter rope segments when damaged. Even after the knot is loaded, it can be untied relatively easily $[60,68]$ and it does not tend to disintegrate under cyclic loading.

Alpine butterfly knot was tested only under cross-load (see Fig. 21). Alpine butterfly knot has the highest efficiency when compared to other cross-loaded knots at a significance level of $5 \%$. This conclusion is supported by a total of 32 measurements performed on one rope and one accessory cord. 


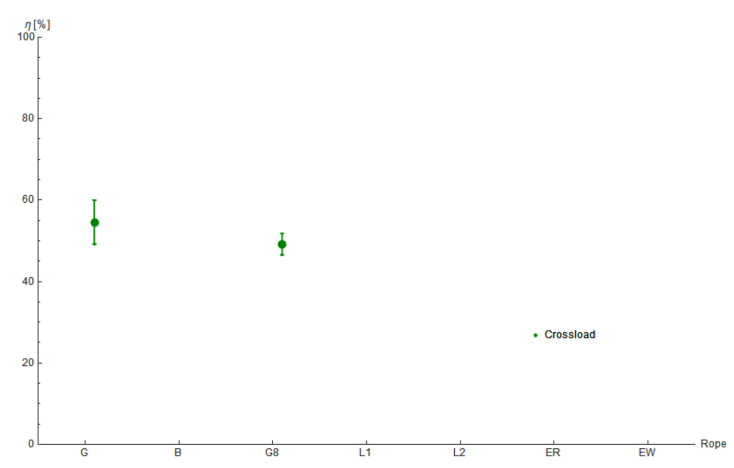

Fig. 21. Alpine butterfly knot efficiency.

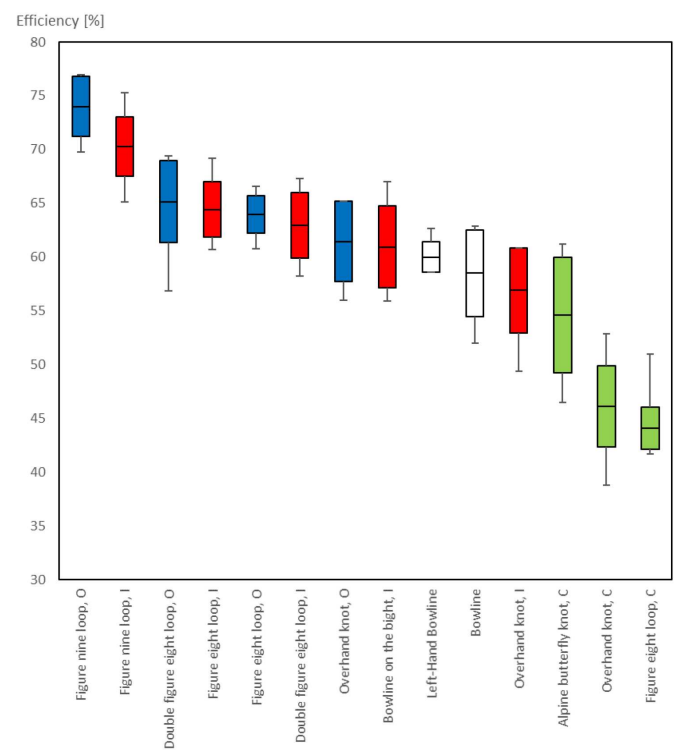

Fig. 22. Loop knots ordered from highest to lowest efficiency (based upon Table V). Mean value, confidence interval $68.27 \%$, and extreme measured values are shown. Blue color is used for standardly loaded loop knots in O geometry, red for I geometry and green for cross-loaded loop knots.

Fall arresting knots on glacier travel should be standardly placed between members of the roped party. Instead of figure eight loop and overhand loop $[40,60,69]$ we recommend to use alpine butterfly. This knot performs much better under crossload and should be preferred for this purpose. The difference in the efficiency compared to the referential cross-loaded figure eight loop is $\Delta \eta=+10.52 \%$. This conclusion is supported by a total of 18 measurements on the same rope.

\subsubsection{Knots comparison}

Knot efficiency was measured on the ropes from various manufacturers, of different diameters and different stages of wear. As we already noticed, such results are not comparable. However, all the analyzed knots were tested on Gilmonte Profistatic rope, which allows us to compare and rank the knot efficiencies (see Table V and Fig. 22). We assume that the results can be applied to any static kernmantle rope with a diameter close to $10.5 \mathrm{~mm}$ and static breaking strength at the level of $30-35 \mathrm{kN}$.
TABLE V

Loop knots ordered from highest to lowest efficiency, measured on static rope Gilmonte Profistatic 10.5. Results were calculated by (3) and coupled into groups. Members of each group are statistically indistinguishable.

\begin{tabular}{|c|c|c|c|}
\hline Loop knots & $\begin{array}{c}\text { Mean } \\
\text { efficiency } \\
{[\%]}\end{array}$ & $\begin{array}{c}\text { Confidence } \\
\text { interval } \\
68.27 \% \\
\end{array}$ & $\begin{array}{c}\text { Difference } \\
\text { from figure } \\
\text { eight loop }\end{array}$ \\
\hline \multicolumn{4}{|c|}{ Standardly loaded loop knots } \\
\hline Figure nine loop, O & 74.00 & $\begin{array}{l}71.19 \\
76.81\end{array}$ & 10.03 \\
\hline Figure nine loop, I & 70.25 & $\begin{array}{l}67.49 \\
73.01\end{array}$ & 5.83 \\
\hline $\begin{array}{l}\text { Double figure } \\
\text { eight loop, O }\end{array}$ & 65.13 & $\begin{array}{l}61.32 \\
68.94\end{array}$ & \\
\hline Figure eight loop, I & 64.42 & $\begin{array}{l}61.87 \\
66.98\end{array}$ & \\
\hline Figure eight loop, $\mathrm{O}$ & 63.97 & $\begin{array}{l}62.20 \\
65.73\end{array}$ & \\
\hline $\begin{array}{l}\text { Double figure } \\
\text { eight loop, I }\end{array}$ & 62.93 & $\begin{array}{l}59.89 \\
65.97\end{array}$ & \\
\hline Overhand knot, O & 61.46 & $\begin{array}{l}57.73 \\
65.21\end{array}$ & -3.29 \\
\hline $\begin{array}{l}\text { Bowline } \\
\text { on the bight, I }\end{array}$ & 60.95 & $\begin{array}{l}57.12 \\
64.77\end{array}$ & \multirow{3}{*}{-4.64} \\
\hline Left-Hand Bowline & 60.00 & $\begin{array}{l}58.57 \\
61.43\end{array}$ & \\
\hline Bowline & 58.51 & $\begin{array}{l}54.48 \\
62.53\end{array}$ & \\
\hline Overhand knot, I & 56.92 & $\begin{array}{l}52.96 \\
60.88 \\
\end{array}$ & -6.39 \\
\hline \multicolumn{4}{|c|}{ Crossloaded loop knots } \\
\hline Alpine butterfly, C & 54.60 & $\begin{array}{l}49.21 \\
60.00 \\
\end{array}$ & 10.52 \\
\hline Overhand, C & 46.12 & $\begin{array}{l}42.34 \\
49.91\end{array}$ & \\
\hline Figure eight, $\mathrm{C}$ & 44.08 & $\begin{array}{l}42.11 \\
46.05\end{array}$ & \\
\hline
\end{tabular}

\subsubsection{Electron microscopy and thermal imaging}

Polyamide microfilaments before and after rope breakage were zoomed using electron microscopy (see Figs. 23 and 24). Intact microfilaments are of cylindrical shape with a constant diameter of $28.85 \pm 0.62 \mu \mathrm{m}$. On the other side, broken fibers have recognizable thickened terminal parts with a mean diameter of $64 \pm 2 \mu \mathrm{m}$. The broken fibers gradually decrease in diameter with increasing distance from the end. After approximately $275 \mu \mathrm{m}$ diameter decreases by a factor of 2 . In the thickened area, the surface of the fibers is covered by flake-like structures (Fig. 24).

Tensile test from the structural point of view can be divided into several temperature intervals $[70,71]$ :

1. As the strain rises, rope temperature increases from the laboratory conditions to a temperature of $50^{\circ} \mathrm{C}$. Young modulus of elasticity can be considered constant within this interval. 


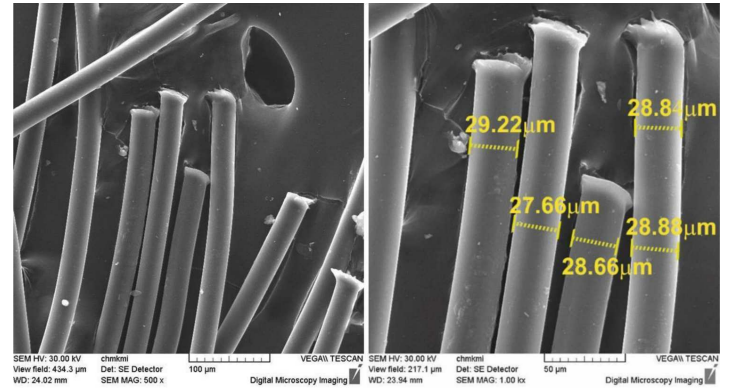

Fig. 23. Electron microscopy digital imaging; terminal parts of polyamide microfilaments cut by a scalpel.

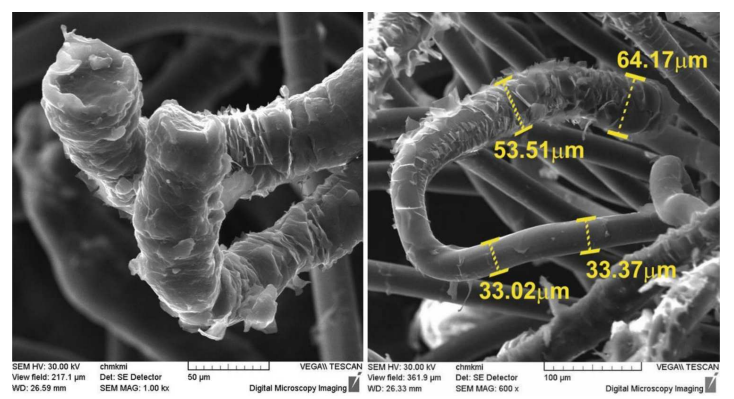

Fig. 24. Electron microscopy digital imaging; terminal parts of polyamide microfilaments torn in tensile tests.

2. Additional increase of strain leads to rising temperature within interval $\left\langle 50^{\circ} \mathrm{C}, 100^{\circ} \mathrm{C}\right)$. Here polyamide crosses the glass-transition temperature $T_{g}$. Within this interval Young modulus of elasticity decreases and polyamide passes from glass state to rubbery state.

3. Further increase of strain leads to rising temperature within interval $\left\langle 100^{\circ} \mathrm{C}, 205^{\circ} \mathrm{C}\right.$ ). The Young modulus of elasticity is even lower than in the previous interval.

4. Temperature interval over $205^{\circ} \mathrm{C}$ covers polyamide melting point temperature $T_{m}$. Within this interval, Young modulus of elasticity reaches zero and rope breaks.

High-speed thermal imaging shows (see Figs. 25-31) that the highest temperature of standardly loaded loop knot just before the knot breaks can be found in the entry part of the stand. The temperature here varies within the interval $\left\langle 60^{\circ} \mathrm{C}, 80^{\circ} \mathrm{C}\right\rangle$, so glass-transition temperature $T_{g}$ is exceeded before breakage.

At the moment when the rope breaks, or after approximately one millisecond after it, the surface temperature of the most exposed parts reach values close to $T_{m}$. Occasionally, even higher temperature than $T_{m}$ was locally detected. At this moment we do not have experimental proof whether the moment when the rope breaks precedes the rapid temperature jump to the interval 4 or vice versa. Without even faster thermal imaging setup we are not

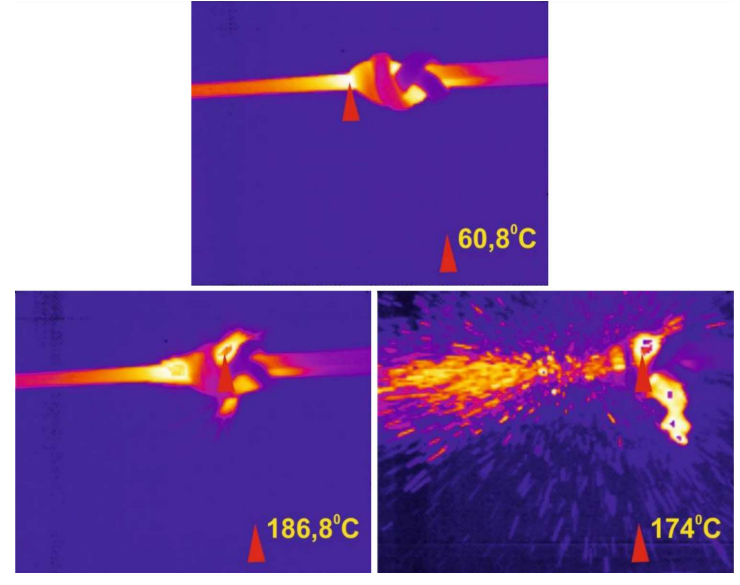

Fig. 25. Thermal imaging of standardly loaded figure eight loop breakage (geometry O).

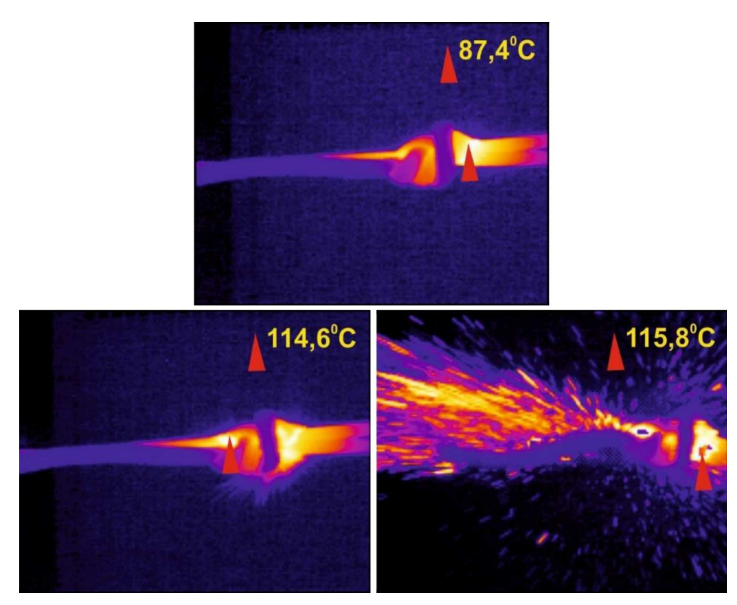

Fig. 26. As in Fig. 25, but for geometry I.

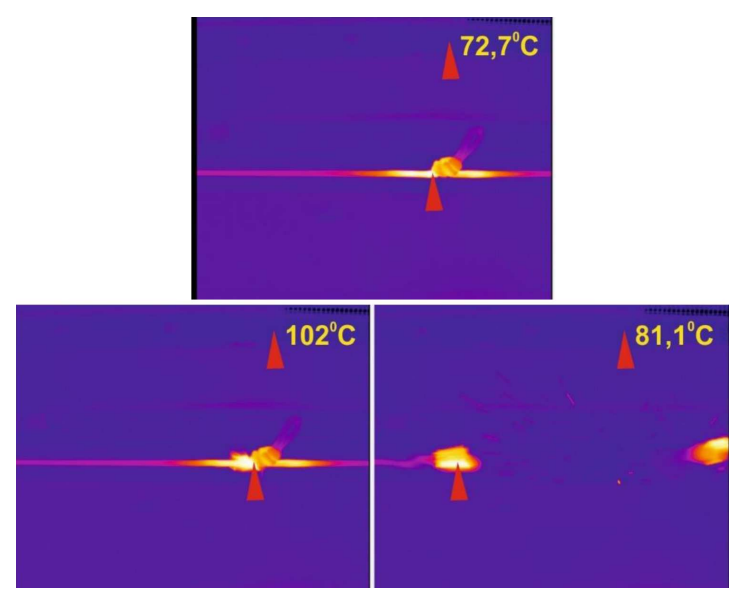

Fig. 27. Thermal imaging of cross-loaded figure eight loop breakage.

able to determine whether the temperature increase causes the rope break, or the event of rope break causes the increase in temperature. Most likely, the truth is somewhere in the middle. At the moment, we neither have a provable explanation for the process of the temperature jump. 


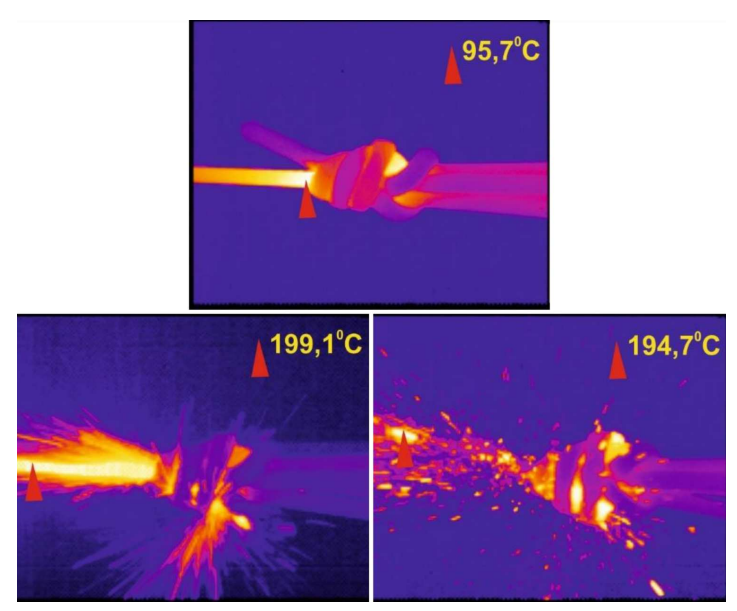

Fig. 28. Thermal imaging of standardly loaded double figure eight loop breakage (geometry $\mathrm{O}$ ).

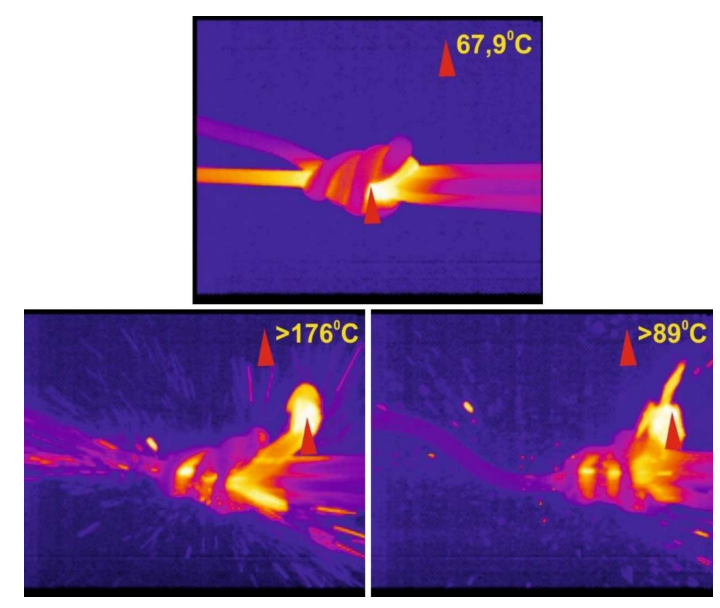

Fig. 29. As in Fig. 28, but for geometry I.

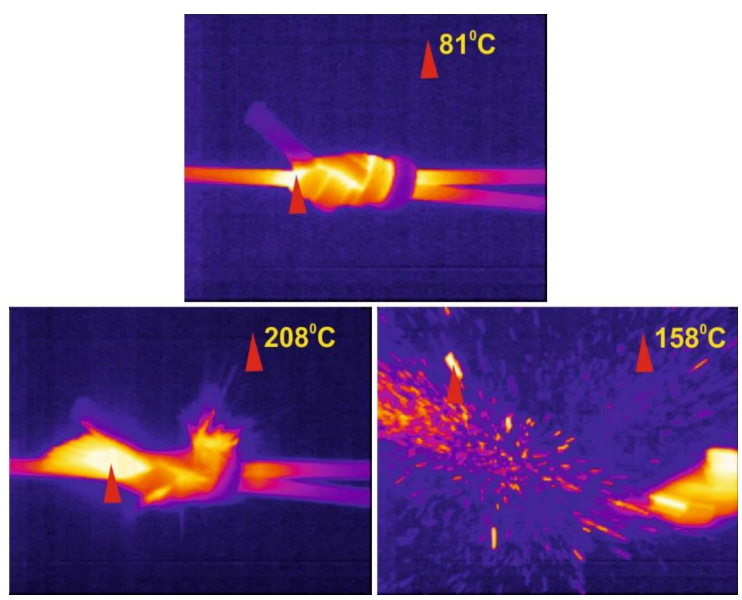

Fig. 30. Thermal imaging of standardly loaded figure nine loop breakage (geometry $\mathrm{O}$ ).

But it is reasonable to say that a significant amount of energy is accumulated into rope just before rope break. Rope absorbs the energy by macroscopic stretching deformation and by change of its microscopic structure orientation to the direction
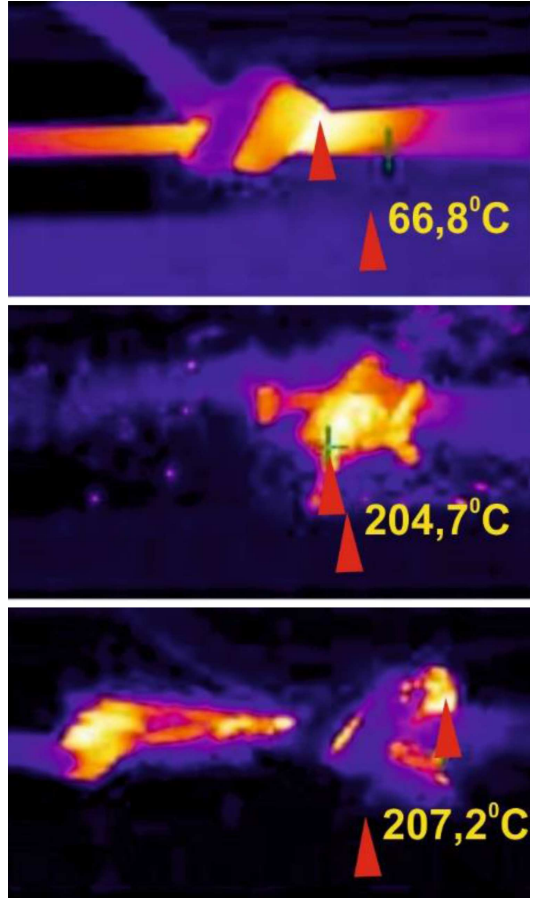

Fig. 31. Thermal imaging of standardly loaded overhand loop breakage (geometry I).

of applied force. As the rope breaks, relaxation and structural reorientation takes place in an extremely short time. At the same time, rope fragments move apart under high friction force generated by the remaining knot body. Both processes can generate sufficient heat attended by the emission of microwave radiation.

The thickening of broken fiber's ends can be expressed by the following hypothesis. At the moment when a rope breaks, or shortly after it, the temperature in the break zone jumps to the level 3 or even 4 using the mechanism described above. Backward movement of disintegrated fragments is highly non-inertial. Molten microfilaments are compressed by a deceleration force. At the same time, temperature quickly decreases and transition from oriented structure to original unoriented structure takes place. Fibers' ends final shape is formed as the surface becomes stable by further cooling down of the material.

\subsection{Future research}

For sure, there are still many topics remaining to be researched. Let us list just a few of them:

1. Presented study deals only with the loop knots. There are many commonly used bends, hitches, or friction hitches that are still uncovered by serious research;

2. The presented study is focused solely on lowstretch ropes designated mainly for work and rescue. Knot efficiencies on dynamic climbing ropes still has not been researched seriously and to a sufficient extent; 
3. Measurements in the presented study were performed at low-speed stretching machine (the speed of jaw movement was set to $180 \mathrm{~mm} / \mathrm{min})$. Rope stretching in real-life applications is almost always faster and more dynamic. The impact of stretching dynamics on knot efficiency remains unclear.

4. The influence of static breaking strength of rope on knot efficiency was proved on figure eight loop and overhand loop. Generalization of this conclusion to all loop knots, or even hitches and bends, requires much more rigorous experimental work;

5. Besides the static breaking strength of a rope, there are many other parameters that may affect the knot efficiency. Hot candidates to be examined are rope diameter, rope wetness, knotability, and smoothness of sheath;

6 . It seems that temperature can play an important role in the process of knot breakage. It changes so fast, that further research would require experimental setup with order of magnitude higher frame rate, i.e., $10^{-5}-10^{-4} \mathrm{~s}$;

7. Improper knot dressing has been recognized by many authors to have a negative impact on the knot efficiency. However, this has never been measured and analyzed seriously.

\section{General conclusions}

The efficiencies of 8 commonly used loop knots were precisely measured, evaluated and analyzed on various low-stretch ropes to an unprecedently large extent. We laid emphasis on high statistical power of performed experiments and precisely controlled experimental methodology, which is extremely important when studying such a heterogeneous structure like a knotted rope. Statistical apparatus for mean knot efficiency and confidence interval evaluation was derived and applied. Properties of studied knots were revised and their mutual comparison was carried out (see Sects. 3.3.1-3.3.9). With a probability bordering on certainty, we may conclude that the efficiency of loop knots is not constant as it is implicitly presented across the vast majority of published works, but it is a decreasing function of static breaking strength of the rope. Furthermore, electron microscopy and high-speed thermal imaging revealed that knotted rope is subjected to temperatures of extraordinary extent as the knot breaks (Sect. 3.3.10). Approximately one millisecond after knot breaks, the surface temperature of the most exposed parts can reach a temperature close to the polyamide melting point.

\section{Acknowledgments}

This work would not have been possible without the material and technical support of the ropemaker company Gilmonte, Slovak mountain rescue service (HZS) and the University of Žilina.
The work was financially supported by Scientific Grant Agency of the Slovak Republic under grant VEGA 1/0795/16, KEGA 040ŽU-4/2018, KEGA 013ŽU-4/2019 and by the Slovak Research and Development Agency under the contract No. APVV0736-12 and No. APVV-14-0096.

\section{References}

[1] G. Marbach, B. Tourte, Alpine Caving Techniques: A Complete Guide to Safe and Efficient Caving, Speleo Projects, Switzerland 2002.

[2] Alpine Club Special Committee, Alpine J. 16, 321 (1864).

[3] C.E.I. Wright, J.E. Magowan, Alpine J. 40, 120 (1928).

[4] D. Himmelfarb, The Technology of Cordage Fibres and Ropes, Leonard Hill, London 1957.

[5] W. Wheelock, Ropes, Knots, and Slings for Climbers, La Siesta Press, 1967.

[6] C.L. Day, The Art of Knotting and Splicing, US Naval Institute Press, 1970.

[7] G.R. Borwick, Alpine J. 78, 62 (1973).

[8] H.F. Microys, Am. Alpine J. 21, 131 (1977).

[9] G. Budworth, The Knot Book, Elliot Right Way Books, 1983.

[10] G. Marbach, J.L. Rocourt, Techniques of the Alpine Speleology, 2nd ed., Techniques Sportives Appliquées, 1980 (in French).

[11] B.F. Bayman, Am. J. Phys. 45, 185 (1977).

[12] J.H. Maddocks, J.B. Keller, SIAM J. Appl. Math. 47, 1185 (1987).

[13] P. Pieranski, S. Kasas, G. Dietler, J. Dubochet, A. Stasiak, New J. Phys. 3, 10 (2001).

[14] N. Clauvelin, B. Audoly, S. Neukirch, J. Mech. Phys. Solids 57, 1623 (2009).

[15] A. Konyukhov, K. Schweizerhof, Proc. Appl. Math. Mech. 10, 177 (2010).

[16] A. Konyukhov, J. Appl. Math. Mech. 95, 406 (2015).

[17] R. Chattopadhyay, Ind. J. Fibre Textile Res. 22, 360 (1997).

[18] A.H. Little, H.L. Parsons, J. Textile Inst. 58, 449 (1967).

[19] P. Schubert, J. Union Int. Associat. Alpinisme 3, 12 (2000).

[20] A.B. Spierings, O. Henkel, M. Schmid, Int. J. Impact Eng. 34, 205 (2007).

[21] C. Arrieta, Yingying Dong, A. Lan, Toan Vu-Khanh, J. Appl. Polym. Sci. 130, 3058 (2013). 
[22] H.A. McKenna, J.V.S. Hearle, N. O'Hear, Handbook of Fibre Rope Technology, Woodhead Publ., Cambridge 2004.

[23] A.J. McLaren, J. Mater. Des. Appl. 220, 1 (2006).

[24] J.A. Frank, J.B. Smith, Rope Rescue Manual, 2nd ed., CMC Rescue Inc., California 1987.

[25] Ch. Warner, in: History and Science of Knots, Eds. J.C. Turner, P. Griend, World Sci. 1998, p. 181.

[26] A. Long, M. Lyon, G. Lyon, Industrial Rope Access - Investigation into Items of Personal Protective Equipment, HSE Books, 2001.

[27] C. Soles, The Outdoor Knots Book, 1st ed., Mountaineers Books, 2004.

[28] K. Phillips, Basic Technical Rescue: National Park Service Search and Rescue, 10th ed., U.S. Department of Interior, National Park Service, 2005.

[29] D. Richards, Nylon Highway 50, 9 (2005).

[30] K.A. Milne, A.J. McLaren, Sports Eng. 9, 1 (2006).

[31] D. Schmidt, D. Clifford, Sail Mag. 2007, 82 (2007).

[32] B. Kane, Arboricult. Urban Forestry 38, 1 (2012).

[33] M. Komorous, B.S. Thesis, Charles University, Prague 2013.

[34] J. McKently, Nylon Highway 59, 4 (2014).

[35] C.W. Ashley, The Ashley Book of Knots, 1st ed., Doubleday \& Co., 1993.

[36] D.F. Merchant, Life on a Line: The Underground Rope Rescue Material, 2nd ed., Lulu Enterprises, 2007.

[37] R. Chisnall, Investigat. Sci. J. 2, 33 (2010).

[38] R. Chisnall, Sci. Justice 56, 282 (2016).

[39] D. Brook, in: BMC, Care \& Maintenance, The British Mountaineering Council, 2001, p. 43.

[40] The Mountaineers, Mountaineering: The Freedom of the Hills, 8th ed., Mountaineers Books, 2010.

[41] The Mountaineers, Mountaineering: The Freedom of the Hills, 9th ed., Mountaineers Books, 2017.

[42] BEAL, BEAL Workbook Pro, 2018.

[43] Edelrid, Ropebook: Looking after Your Rope, 2018.

[44] Edelweiss, Catalogue PRO 2018, Standards, The Low-Stretch Ropes, p. 4, 2018.

[45] Gilmonte, The Lifespan of Ropes, 2019.

[46] Tendon, Lifespan: Ageing of Dynamic Ropes in Use, 2019.
[47] P. Schubert, Sicherheit und Risiko in Fels und Eis: Band 1, 9th ed., Bergverlag Rother, 2016.

[48] S. Ingram, in: BMC. Care $\&$ Maintenance, The British Mountaineering Council, 2001, p. 54 .

[49] A Guide for Climbers and Mountaineers: Ropes - Care and Maintenance, The British Mountaineering Council, 2014, p. 19.

[50] M. Honner, P. Litoš, M. Švantner, Infrared Phys. Technol. 45, 131 (2004).

[51] "Effective Directional Emissivity at High Temperature (EDEHT)", New Technologies Research Center (NTRC), University of West Bohemia, 2019.

[52] T. Frank, V. Urbanová, Lana a uzly pro horolezce a jeskyñáře, 2nd ed., Krasová sekce České speleologické společnosti, Praha 2001 (in Czech).

[53] T. Frank, T. Kublák, Horolezecká abeceda, Epocha, Praha 2007 (in Czech).

[54] T. Kublák, Mountaineering Methodology. Part 1 - The Basics MMP Publ., 2014.

[55] A. Wairld, Vertical: A Technical Manual for Cavers, Speleological Research Council Ltd., 1988.

[56] J. Janiga, I. Krajčír, M. Sekelský, I. Račko, J. Pet'o, M. Lizuch, M. Kupčo, K. Rázusová, Sylaby horských záchranárov: III Postupy, 1st ed., Horská záchranná služba, 2006 (in Slovak).

[57] A. Tyson, M. Loomis, Climbing Self Rescue: Improvising Solutions for Serious Situations, Mountaineers Books, 2006.

[58] Knots, The British Mountaineering Council, 2009.

[59] D. Fasulo, Self-Rescue, 2nd ed., Rowman and Littlefield, 2011.

[60] P. Descamps, et al., Alpine Skills: Summer, 2nd Engl. ed., UIAA, 2015.

[61] N. Montgomery, Single Rope Techniques, Sydney Speleological Society, 1977, p. 10.

[62] B. Smith, A. Padgett, On Rope: North American Vertical Rope Techniques for Caving, 2nd ed., Natl. Speleological Society, 1997.

[63] A. Detter, Ch. Cowell, L. McKeown, P. Howard, Health and Safety Executive, 2008.

[64] T. Vines, S. Hudson, High Angle Rope Rescue Techniques, Levels I and II, Jones and Bartlett Publ., 2014.

[65] T. Evans, "A Review of Knot Strength Testing", in: Int. Techn. Rescue Symp., (2016).

[66] W. Storage, J. Ganter, Georgia Underground 35, 1 (2000). 
The 100 years anniversary of the Polish Physical Society - the APPA Originators

[67] M. Gommers, "An Analysis of Bowlines", Nylon Highway 59, 3 (2014).

[68] B. Tilton, Outward Bound Ropes, Knots, and Hitches, Falcon Guides, 2012.

[69] P. Schubert, Alpine Seiltechnik, Beverlag Rother, 2017.
[70] T. Liptáková, P. Alexy, E. Gondár, V. Khunová, Polymérne konštrukčné materiály, EDIS, 2012 (in Slovak).

[71] E. Parodi, Ph.D. Thesis, Technische Universiteit Eindhoven, 2017. 